\title{
Effect of allopurinol on diabetic nephropathy; a double- blind clinical trial study
}

\author{
Saeed Mardani $^{\circledR}$, Farzaneh Kadkhodaei-Elyaderani*, Ali Momeni, Maryam Saeedi \\ Department of Internal Medicine, School of Medicine, Shahrekord University of Medical Sciences, Isfahan, Iran
}

\section{AR T I C L E I N F O}

Article Type:

Original

\section{Article History:}

Received: 8 April 2020

Accepted: 8 June 2020

Published online: 26 July 2020

Keywords:

Diabetic nephropathy

Allopurinol

Uric acid

Diabetic kidney disease

\begin{abstract}
A B S T R A C T
Introduction: Diabetic nephropathy (diabetic kidney disease) is the most common cause of renal failure.

Objectives: Regarding the role of allopurinol in the improvement of diabetic kidney disease, this study aimed to investigate the ameliorative effect of allopurinol in diabetic nephropathy patients.

Patients and Methods: This double-blind clinical trial study was performed on 60 patients with diabetic kidney disease referenced to nephrology clinic during 2019-2020. Patients were divided into case (treated with allopurinol $100 \mathrm{mg} / \mathrm{d}$ ) and control (received placebo pill) groups. Three and six months of intervention, complete blood count (CBC), fasting blood sugar levels (FBS), serum blood urea nitrogen (BUN) levels, creatinine (Cr) and uric acid (UA) levels, 24 hours urinary protein, glomerular filtration rate (GFR), neutrophil-lymphocyte ratio (NLR) and platelet-lymphocyte ratio (PLR) were measured and compared between the two groups.

Results: After six months, reduction of UA and 24 hours urinary protein were not significant in the control group $(P>0.05)$ but it was significant in the allopurinol group $(P<0.05)$. In the allopurinol group, NLR and PLR levels decreased significantly during the six months $(P<0.01)$ however there was no significant change in the control group $(P>0.05)$.

Conclusion: Low dosage of allopurinol $(100 \mathrm{mg} / \mathrm{d})$ reduces UA, proteinuria, NLR and PLR in patients after six months. Therefore it can be used for diabetic nephropathy patients as a supplementary, inexpensive and safe treatment.

Trial registration: The trial protocol was approved by the Iranian Registry of Clinical Trials (identifier: IRCT20200117046158N1; https://irct.ir/trial/45533, ethical code; IR.SKUMS. REC.1397.303).
\end{abstract}

Implication for health policy/practice/research/medical education:

In this study, 60 patients with diabetic kidney disease divided into two groups. Patients in the intervention group were treated with allopurinol pill and patients in the control group received placebo pill. The results of this study showed that allopurinol can play a significant role in reducing uric acid and 24-hour urine protein levels without significant changes in the patients' blood factors.

Please cite this paper as: Mardani S,. Effect of allopurinol on diabetic nephropathy; a double-blind clinical trial study. J Renal Inj Prev. 2021; 10(1): e03. doi: 10.34172/jrip.2021.03.

\section{Introduction}

In developing countries, diabetes mellitus is the leading cause of chronic renal failure and is considering the cause of more morbidity and mortality worldwide. Both types of diabetes, but principally type I, plays an important role in this problem due to its complications $(1,2)$. Two types of diabetic patients experience same stages of clinical and pathogenic kidney damages such as kidney hypertrophy, primary nephropathy (micro-albuminuria, obvious nephropathy (macro-albuminuria) and finally ESRD (end-stage renal disease) which is detected by urinary protein excretion, high blood pressure and reduction in kidney function up to $90 \%$ (1).

Diabetic nephropathy (diabetic kidney disease), among all these complications, has become the main cause of end-stage renal failure and cardiovascular mortality that would happen after many years of diabetes onset $(1,3)$.

Some medicines are used to prevent the progression of diabetic nephropathy such as angiotensin-converting enzyme (ACE) and, angiotensin II receptor blockers (ARBs) (4).

Administration of these drugs in micro-albuminuria 
stage can reduce albuminuria, however in obvious albuminuria these drugs may slow the course of nephropathy and reduce proteinuria without complete improvement (1).

Previous studies on the role of uric acid in the development of renal failure have shown that uric acid levels are higher in patients with diabetes than in the general population $(5,6)$. Additionally, the progression of diabetic nephropathy was faster in patients with higher serum uric acid levels (7).

Therefore, uric acid-lowering agents such as allopurinol may be effective in treating diabetic nephropathy $(8,9)$. Animal studies have shown that allopurinol can reduce kidney damages due to inhibition of lipid peroxidation (10). In addition, by reducing serum uric acid levels, allopurinol ameliorates histological changes and improves renal function (11).

Recent clinical trials by evaluating the impact of allopurinol on reduction of proteinuria and improving renal function in diabetic nephropathy have shown that its low-dose $(100 \mathrm{mg} /$ daily) reduces proteinuria in the patients and is effective in increasing GFR (glomerular filtration rate) levels and also reducing serum uric acid levels $(12,13)$. Therefore, they suggested that allopurinol may be useful as a supplementary drug in treatment of patients with diabetic nephropathy with fewer side effects, since it can play an effective role in improving kidney function by reduction of uric acid and proteinuria.

\section{Objectives}

This study evaluated the effect of allopurinol on the uric acid (UA) and 24-hour urine protein levels and inflammatory factors including neutrophil to lymphocyte ratio (NLR) and platelet to lymphocyte ratio (PLR) in patients with diabetic kidney disease.

\section{Patients and Methods \\ Study design}

This double-blind clinical trial study was conducted on 60 diabetic nephropathy patients referred to university clinics of Shahrekord during 2019-2020. This sample was selected from eligible patients by convenience random sampling. Inclusion criteria were having more than $150 \mathrm{mg}$ protein in 24 hours urine, serum uric acid levels between 6 to $15 \mathrm{mg} / \mathrm{dL}$, bland urinary sediment and being satisfied to participate. Patients with significant kidney failure (serum creatinine $>3 \mathrm{mg} / \mathrm{dL}$ ) or glomerular filtration rate $<25 \mathrm{cc} / \mathrm{min}$ (based on MDRD formula) or previously use of allopurinol, remarkable drug complications during the study such as nausea, vomiting, diarrhea, fever, sore throat, itching, blisters, swelling and hives, dermatitis, headache and shortness of breath, increased liver enzymes, cytopenia or unwillingness to continue the study were excluded.

At first demographic information such as age, gender, height, weight, body mass index (BMI), systolic blood pressure (SBP), diastolic blood pressure (DBP), glycated hemoglobin (HbAlc), level, diabetes duration, background disease (hypertension and ischemic heart disease), diabetes retinopathy, coronary artery bypass graft surgery, hypothyroidism and drugs (insulin or antidiabetes oral medicines) were recorded.

At first, 60 patients were randomly allocated and divided into two groups through randomized block design (20 blocks of 3 to complete the two group of 30) (Figure 1).

Patients in both groups received anti-hypertensive, ACE inhibitors and ARBs according to the previous regimen which was continued unchanged during the study. However, if a new antihypertensive drug was needed we prescribed a drug with no effect on proteinuria in the patients.

The control group received placebo and intervention group received the allopurinol $100 \mathrm{mg} / \mathrm{d}$ (Darou Pakhsh Pharmaceutical Co., Isfahan, Iran).

For blinding before intervention; both drugs (allopurinol and placebo) were prepared with the same color and shape as the wheat flour and powdered allopurinol which were inserted in similar capsules respectively and labeled as A and $\mathrm{B}$ before giving to patients.

The tests of complete blood count (CBC), fasting blood sugar (FBS) levels, blood urea nitrogen (BUN) levels, serum creatinine (Cr) level, uric acid (UA) level and 24-hour urine protein level, NLR, PLR and GFR were assessed at the beginning of the study and three and six months after intervention again.

\section{Ethical issues}

The research was conducted in accordance with the Declaration of Helsinki as a statement of ethical principles for medical research. The ethics committee of Shahrekord University of Medical Sciences approved the study (\#IR. SKUMS.REC.1397.303). Accordingly, written informed consent was taken from all participants before any intervention. This study was resulted from the residential thesis by Farzaneh Kadkhodaei-Elyaderani at department of internal medicine of this university. Additionally, the trial protocol was approved by the Iranian Registry of Clinical Trials (identifier: IRCT20200117046158N1; https://irct.ir/ trial/45533).

\section{Statistical analysis}

The collected data was entered into SPSS software (version 23). Based on the Kolmogorov-Smirnov test results the distribution of variables such as age, weight, height, BMI, white blood cell (WBC), PLT, Hb, UA and FBS were normal therefore, parametric tests including independent $\mathrm{t}$-test and for repeated measures the ANOVA test was used. However, according to the results of the Kolmogorov-Smirnov test on the abnormal distribution of 24-hour urine protein, the nonparametric tests including 


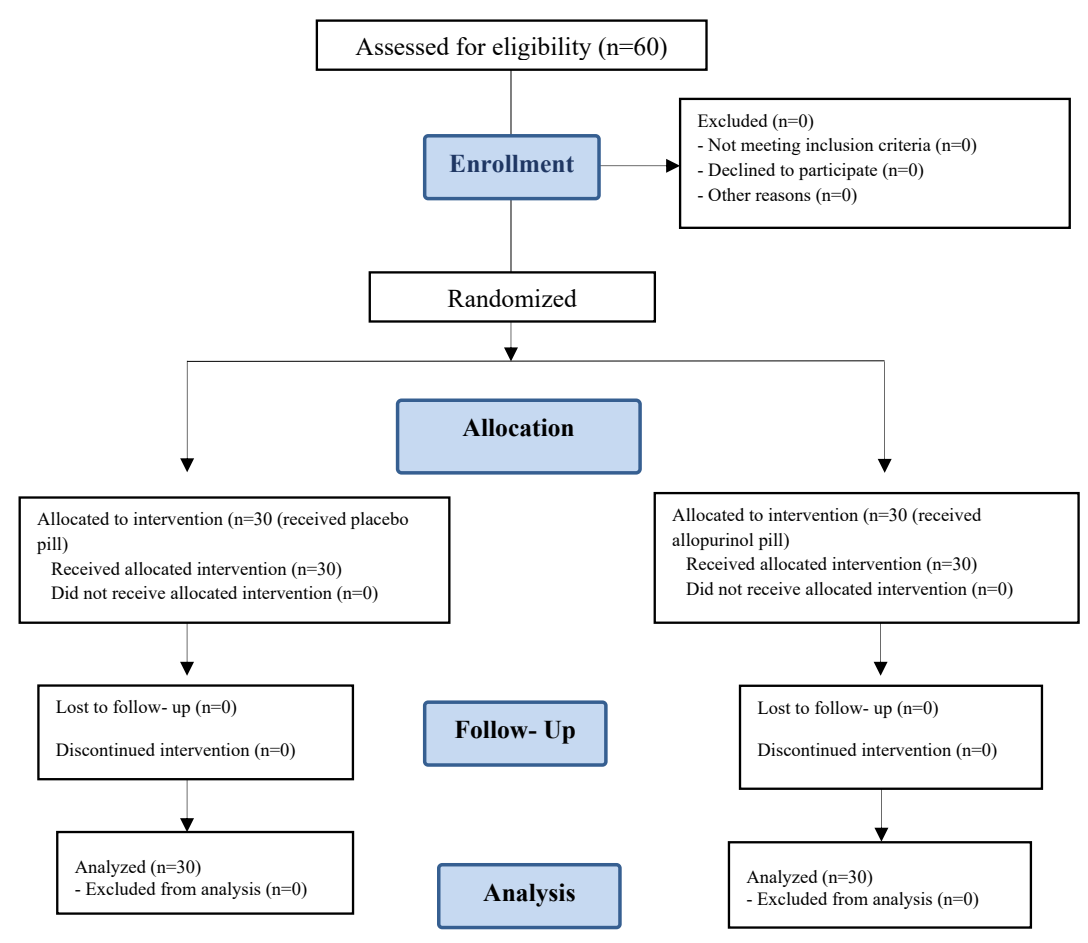

Figure 1. Consort flow chart.

the Mann-Whitney $U$ and Friedman tests were used. In addition, the chi-square and the Fisher's exact test were used to compare the frequency distribution of qualitative data. In all statistical analyzes, the significance level was considered less than 0.05 .

\section{Results}

In the present study, of 60 patients with diabetic nephropathy, 17 were male (56.7\%) and 13 were females $(43.3 \%)$ with the mean age of $65.3 \pm 9.75$ years in the control group and mean age of $65.63 \pm 11.28$ years in the allopurinol group. Allopurinol group consisted of 15 males (50\%) and 15 females (50\%). According to Table 1 , no significant difference between the two groups was seen $(P>0.05$; Table 1$)$.

There was no significant difference in CBC, FBS, BUN and $\mathrm{Cr}$ between two groups at three investigated times $(P>0.05)$. In addition, 6 months after the start of the study, changes in these parameters over time were not significant in both groups $(P>0.05$; Table 2$)$.

Before intervention, there was no significant difference in UA level between the control group with the mean of $7.02 \pm 1.16 \mathrm{mg} / \mathrm{dL}$ and allopurinol group with the mean of $7.14 \pm 0.98 \mathrm{mg} / \mathrm{dL}(P>0.05)$. Between groups comparison showed that after three and six months of intervention; UA levels were significantly different in allopurinol group with the mean of $5.87 \pm 1.22 \mathrm{mg} / \mathrm{dL}$ and $4.99 \pm 1.18 \mathrm{mg} /$ $\mathrm{dL}$ and in the control group with the mean of $6.89 \pm 0.89$ $\mathrm{mg} / \mathrm{dL}$ and $7.09 \pm 1.39 \mathrm{mg} / \mathrm{dL}(P<0.05)$. Within groups comparison showed that after six months of the study onset, UA and 24-hour urine protein changes were not significant in the control group $(P>0.05)$, however, during this time, a significant decrease in the level of these two parameters was observed in the allopurinol group $(P<0.05$; Table 3$)$.

In addition, NLR and PLR levels were not significantly different between the two groups before the intervention $(P>0.05)$. However 6 months after intervention, the NLR level in the allopurinol group with the mean of $2.16 \pm$ 0.41 was significantly lower than the control group with the mean of $2.48 \pm 0.62(P=0.017)$. Additionally, in the control group no significant changes in NLR and PLR levels were seen after 6 months of intervention $(P>0.05)$; since in the allopurinol group, these two factors had a significant decrease $(P<0.01$; Table 4$)$.

Finally, it was indicated that the mean of GFR did not differ significantly between the two groups in any of the three times $(P>0.05)$. In addition, 6 months after the study, GFR changes were not significant in the two groups $(P>0.05$; Table 5).

\section{Discussion}

The current study was conducted on 60 diabetic nephropathy patients assigned to the control and allopurinol groups with the aim of investigating the effect of allopurinol on uric acid. The two mentioned groups were similar in the basic factors such as age, gender, BMI, SBP, DBP and HbA1c levels $(P>0.05)$. In addition, the results of the preliminary blood tests, including $\mathrm{CBC}$, FBS, BUN and $\mathrm{Cr}$ in none of the three trial times (before 
Table 1. Patients basic factors in the two groups

\begin{tabular}{|c|c|c|c|}
\hline Characteristics & Control group $(n=30)$ & Allopurinol group $(n=30)$ & $P$ value \\
\hline \multicolumn{4}{|l|}{ Gender } \\
\hline Male & $17(56.7 \%)$ & $15(50 \%)$ & \multirow{2}{*}{0.796} \\
\hline Female & $13(43.3 \%)$ & 15 (50\%) & \\
\hline Age (year) & $65.03 \pm 9.75$ & $65.63 \pm 11.28$ & 0.826 \\
\hline Weight (kg) & $82.70 \pm 15.98$ & $80.32 \pm 14.28$ & 0.545 \\
\hline Height $(\mathrm{cm})$ & $176.47 \pm 55.34$ & $165.33 \pm 9.37$ & 0.282 \\
\hline BMI $\left(\mathrm{kg} / \mathrm{m}^{2}\right)$ & $28.89 \pm 7.01$ & $29.47 \pm 5.50$ & 0.723 \\
\hline SBP (mm Hg) & $132.67 \pm 15.07$ & $128.33 \pm 10.85$ & 0.206 \\
\hline $\mathrm{DBP}(\mathrm{mm} \mathrm{Hg})$ & $80 \pm 0$ & $80 \pm 0$ & 1.00 \\
\hline HbA1c (\%) & $7.32 \pm 0.81$ & $7.24 \pm 0.98$ & 0.738 \\
\hline \multicolumn{4}{|l|}{ Underlying diseases } \\
\hline Diabetes duration (year) & $13.37 \pm 6.62$ & $12.90 \pm 6.47$ & 0.783 \\
\hline Hypertension & $28(93.3 \%)$ & $28(93.3 \%)$ & 1.00 \\
\hline Hypertension duration (year) & $12.17 \pm 7.36$ & $11.07 \pm 6.04$ & 0.529 \\
\hline Ischemic heart disease & $4(13.3 \%)$ & $3(10 \%)$ & 0.688 \\
\hline Diabetic retinopathy & $5(16.7 \%)$ & $5(16.7 \%)$ & 1.00 \\
\hline Coronary artery bypass surgery & $1(3.3 \%)$ & $2(6.7 \%)$ & 1.00 \\
\hline \multicolumn{4}{|l|}{ Medications } \\
\hline Insulin & $18(60 \%)$ & $15(50 \%)$ & 0.604 \\
\hline Oral anti-diabetic medications & $16(53.3 \%)$ & $17(56.7 \%)$ & 0.795 \\
\hline Both oral and insulin medications & $4(13.3 \%)$ & $2(6.7 \%)$ & 0.389 \\
\hline Losartan & $25(83.3 \%)$ & $24(80 \%)$ & 0.739 \\
\hline Thyroid medications & $0(0 \%)$ & $3(10 \%)$ & 0.086 \\
\hline
\end{tabular}

Abbreviation: BMI, body mass index; SBP, systolic blood pressure; DBP, diastolic blood pressure; HbA1c, glycated hemoglobin.

Table 2. Comparison of patients' blood parameters during the 3 time period in the two groups

\begin{tabular}{|c|c|c|c|c|}
\hline Variables & Time & Control group $(n=30)$ & Allopurinol group $(n=30)$ & $P$ value ${ }^{a}$ \\
\hline & Before intervention & $6.57 \pm 1.96$ & $7.35 \pm 1.73$ & 0.108 \\
\hline \multirow[t]{2}{*}{ WBC $\left(\times 10^{3} / \mu \mathrm{L}\right)$} & 3 months after intervention & $7.08 \pm 1.62$ & $7.99 \pm 1.06$ & 0.335 \\
\hline & 6 months after intervention & $7.12 \pm 1.61$ & $7.31 \pm 1.70$ & 0.657 \\
\hline \multirow[t]{2}{*}{$P$ value $^{\mathrm{b}}$} & & 0.157 & 0.368 & \\
\hline & Before intervention & $14.03 \pm 2.16$ & $14.23 \pm 1.88$ & 0.708 \\
\hline \multirow[t]{2}{*}{$\mathrm{Hb}(\mathrm{g} / \mathrm{dL})$} & 3 months after intervention & $14.15 \pm 1.91$ & $14.30 \pm 1.82$ & 0.757 \\
\hline & 6 months after intervention & $13.91 \pm 1.87$ & $14.47 \pm 1.96$ & 0.259 \\
\hline \multirow[t]{2}{*}{$P$ value ${ }^{b}$} & & 0.336 & 0.182 & \\
\hline & Before intervention & $223.60 \pm 81.77$ & $223.90 \pm 66.73$ & 0.988 \\
\hline \multirow[t]{2}{*}{ PLT count $\left(\times 10^{3} / \mu \mathrm{L}\right)$} & 3 months after intervention & $215.37 \pm 80.36$ & $224.13 \pm 63.56$ & 0.641 \\
\hline & 6 months after intervention & $224.67 \pm 88.80$ & $221.93 \pm 61.54$ & 0.890 \\
\hline \multirow[t]{2}{*}{$P$ value $^{b}$} & & 0.368 & 0.862 & \\
\hline & Before intervention & $133.37 \pm 36.05$ & $129.63 \pm 27.36$ & 0.653 \\
\hline \multirow[t]{2}{*}{$\mathrm{FBS}(\mathrm{mg} / \mathrm{dL})$} & 3 months after intervention & $136.67 \pm 30.08$ & $127.93 \pm 25.32$ & 0.229 \\
\hline & 6 months after intervention & $134.00 \pm 30.99$ & $128.03 \pm 35.56$ & 0.494 \\
\hline \multirow[t]{2}{*}{$P$ value $^{b}$} & & 0.802 & 0.907 & \\
\hline & Before intervention & $27.97 \pm 14.64$ & $25.61 \pm 13.01$ & 0.512 \\
\hline \multirow[t]{2}{*}{ BUN (mg/dL) } & 3 months after intervention & $26.13 \pm 10.51$ & $25.57 \pm 15.83$ & 0.873 \\
\hline & 6 months after intervention & $27.53 \pm 11.41$ & $26.09 \pm 13.78$ & 0.660 \\
\hline \multirow[t]{2}{*}{$P$ value $^{b}$} & & 0.415 & 0.877 & \\
\hline & Before intervention & $1.49 \pm 0.54$ & $1.36 \pm 0.39$ & 0.284 \\
\hline \multirow[t]{2}{*}{$\mathrm{Cr}(\mathrm{mg} / \mathrm{dL})$} & 3 months after intervention & $1.49 \pm 0.49$ & $1.41 \pm 0.42$ & 0.468 \\
\hline & 6 months after intervention & $1.49 \pm 0.50$ & $1.39 \pm 0.44$ & 0.407 \\
\hline$P$ value ${ }^{b}$ & & 0.971 & 0.507 & \\
\hline
\end{tabular}

Abbreviation: WBC, white blood cell; PLT, platelet; FBS, fasting blood sugar; BUN, serum urea nitrogen; Cr, Creatinine.

a The significance level obtained from the independent $t$-test in comparison of the mean of the variable between the two groups.

${ }^{\mathrm{b}}$ Significant level of Repeated measure ANOVA to compare the mean variable over time in each of the two groups. 
Table 3. Comparison of the mean level of uric acid (UA) and 24-hour urine protein levels in patients of the two groups at the three times

\begin{tabular}{|c|c|c|c|c|}
\hline Variables & Time & Control group $(n=30)$ & Allopurinol group $(n=30)$ & $P$ value \\
\hline \multirow{3}{*}{ Uric Acid; mg/dL } & Before intervention & $7.02 \pm 1.16$ & $7.14 \pm 0.98$ & $0.690^{\mathrm{a}}$ \\
\hline & 3 months after intervention & $7.09 \pm 1.39$ & $5.87 \pm 1.22$ & $0.001^{\mathrm{a}}$ \\
\hline & 6 months after intervention & $6.89 \pm 0.89$ & $4.99 \pm 1.18$ & $<0.001^{\mathrm{a}}$ \\
\hline$P$ value $^{c}$ & & 0.488 & $<0.001$ & \\
\hline \multirow{3}{*}{$\begin{array}{l}24 \text { hour urine protein; } \\
\mathrm{mg} / \mathrm{d}\end{array}$} & Before intervention & $\begin{array}{c}504.98 \pm 556.16 \\
221.50(170-625)\end{array}$ & $\begin{array}{c}687.40 \pm 743.04 \\
330(170-988.75)\end{array}$ & $0.286^{b}$ \\
\hline & 3 months after intervention & $\begin{array}{c}558.63 \pm 607.93 \\
229(178.75-690)\end{array}$ & $\begin{array}{c}605.09 \pm 727.79 \\
258.50(154.50-820.15)\end{array}$ & $0.789^{b}$ \\
\hline & 6 months after intervention & $\begin{array}{c}517.80 \pm 525.39 \\
252.50(177-725)\end{array}$ & $\begin{array}{c}494.10 \pm 576.81 \\
258.50(154.50-729.50)\end{array}$ & $0.868^{b}$ \\
\hline$P$ value ${ }^{c}$ & & 0.547 & 0.002 & \\
\hline
\end{tabular}

Data are shown with mean \pm SD or median (interquartile range, IQR).

a The significance level obtained from the independent t-test in comparison of the mean of the variable between the two groups.

${ }^{b}$ The significance level of the Mann-Whitney test in comparison of the mean of the variable between the two groups.

'Significant level obtained from repeated measure ANOVA in comparison of the mean of the variable over the time in each of the two groups.

${ }^{\mathrm{d}}$ Significant level of Friedman test to compare the mean of the variable over time in each of the two groups.

Table 4. Comparison of mean NLR and PLR during the 3 time period in the two groups

\begin{tabular}{|c|c|c|c|c|}
\hline Variables & Time & Control group $(n=30)$ & Allopurinol group $(n=30)$ & $P$ value $^{\text {a }}$ \\
\hline \multirow{3}{*}{ NLR } & Before intervention & $2.57 \pm 0.57$ & $2.69 \pm 0.43$ & 0.387 \\
\hline & 3 months after intervention & $2.59 \pm 0.54$ & $2.38 \pm 0.46$ & 0.128 \\
\hline & 6 months after intervention & $2.48 \pm 0.62$ & $2.16 \pm 0.41$ & 0.017 \\
\hline \multirow[t]{2}{*}{$P$ value $^{b}$} & & 0.194 & $<0.001$ & \\
\hline & Before intervention & $7.16 \pm 2.66$ & $7.36 \pm 2.41$ & 0.756 \\
\hline \multirow[t]{2}{*}{ PLR } & 3 months after intervention & $7.08 \pm 3.13$ & $6.97 \pm 2.11$ & 0.866 \\
\hline & 6 months after intervention & $7.42 \pm 2.98$ & $6.62 \pm 2.20$ & 0.239 \\
\hline$P$ value ${ }^{b}$ & & 0.510 & 0.004 & \\
\hline
\end{tabular}

Data are shown with mean \pm SD.

PLR: platelet/lymphocyte ratio, NLR: neutrophil/lymphocyte ratio.

a The significance level obtained from the independent t-test in comparison of the mean of the variable between the two groups.

${ }^{a}$ Significant level obtained from repeated measure ANOVA in comparison of the mean of the variable over the time in each of the two groups.

Table 5. Determination and comparison of the mean GFR in patients of the two groups at the three times

\begin{tabular}{|c|c|c|c|c|}
\hline Variables & Time & Control group $(n=30)$ & Allopurinol group $(n=30)$ & $P$ value $^{a}$ \\
\hline \multirow{3}{*}{ GFR $\left(\mathrm{mL} / \mathrm{min} / 1.73 \mathrm{~m}^{2}\right)$} & Before intervention & $50.91 \pm 17.22$ & $54.03 \pm 19.05$ & 0.508 \\
\hline & 3 months after intervention & $49.75 \pm 17.57$ & $51.97 \pm 18.56$ & 0.636 \\
\hline & 6 months after intervention & $50.79 \pm 19.10$ & $53.24 \pm 18.81$ & 0.619 \\
\hline$P$ value ${ }^{b}$ & & 0.518 & 0.532 & \\
\hline
\end{tabular}

GFR: glomerular filtration rate.

a The significance level obtained from the independent $t$ test compared to the mean of the variable between the two groups.

${ }^{b}$ Significant level of repeated measure ANOVA to compare the mean variable over time in each of the two groups.

the intervention and at three and six months after the intervention) had no significant difference between the two groups $(P>0.05)$.

Therefore it seems that the biggest strength of the present study is the two study groups were matched in terms of confounding and possible factors affecting the impact of allopurinol on uric acid in diabetic nephropathy patients since they were not significantly different. Most of previous studies refer to factors such as patients' age
(14), obesity and over-weight (15), hypertension (16) diabetes duration (14) and hemoglobin levels (17) which are significant risk factors of diabetic nephropathy.

Evaluation of UA mean level showed that before intervention, UA level had no significant difference between the two groups $(P>0.05)$. After three and six months of intervention; UA level in the allopurinol group was significantly lower than the control group $(P<0.05)$. After 6 months of the study beginning; UA changes were 
not significant in the control group; but in the allopurinol group it was seen a significant reduction in UA levels $(P<0.05)$.

Explaining this finding, UA levels are directly related to urinary albumin excretion, and in diabetic nephropathy patients, serum uric acid levels are higher than healthy individuals. Additionally, in patients with type 2 diabetes, hyperuricemia is associated with peripheral arterial disease, hypertension, higher glyceridemia, higher HbAlc, higher albuminuria, and lower GFR. It was shown a significant relationship between higher level of UA and diabetic nephropathy disease (18). Along this case, many studies were done to investigate the effect of allopurinol on UA reduction. Allopurinol as a safe drug can reduce UA level in diabetic nephropathy patients and resulted to lower risk of kidney diseases $(13,19,20)$. Wei et al concluded that allopurinol consumption causes to UA concentration reach the proper level in $44.6 \%$ of patients that it was more common in males. They found a strong relationship between allopurinol dosage and desired UA concentration (21).

The results of our study showed that the mean of 24-hours urine protein was not significant in the three trial times between the two groups $(P>0.05)$. After six months of the study beginning, within group comparison revealed that this parameter had a significant decrease in the case group $(P<0.05)$ but a non-significant decrease was seen in the control group $(P>0.05)$. Similar studies have suggested that allopurinol may reduce the amount of 24-hours urine protein $(12,22-24)$. In fact, the earliest sign of diabetic nephropathy is the increase of urinary albumin excretion. Over time, protein excretion rises and even reaches more than a few grams per day. At this stage, due to high urine protein excretion, the concentration of protein decreases in blood and the possibility of ankle swelling (environmental edema) increases and body fluids balance would be disturbed. Thereby, proteinuria is the main characteristic of diabetic nephropathy and in diagnostic cases it is necessary to annual measurement. Allopurinol is one of the effective medicines to reduce urine protein. By lowering the level of UA, this drug inhibits the effect of uric acid on glomeruli and renal vessels and reduces proteinuria. Therefore, this drug can indirectly reduce the risk of kidney disease in diabetic nephropathy patients.

In addition, the results of the present study showed no significant difference between the two groups before and 3 months after the intervention, but 6 months after intervention, the mean of NLR in the allopurinol group was significantly lower than the control group. Generally, administration of allopurinol during the 6 months can significantly reduce the level of inflammatory parameters such as NLR and PLR.

It should be noted that the inflammation plays an important role in development of diabetic nephropathy, including the increased chemokine production, infiltration of inflammatory cells to the kidney, production of proinflammatory cytokine and tissue damage. Inflammatory process in the kidneys activates with several components of the diabetic milieu, as hyperglycemia, renin-angiotensin system and oxidative stress, which leads to infiltration of the organ by monocytes and lymphocytes, which secrete injurious molecules, such as proinflammatory cytokines and reactive oxygen species. This leukocyte activity increases the inflammatory response and improves cell injury and development of fibrosis. In diabetic kidneys better understanding of the inflammatory response is expected to identify the new anti-inflammatory strategies for the potential treatment of human diabetic nephropathy (25).

Therefore, the results of many previous studies have indicated a significant relationship between leukocytosis, lymphocyte count and diabetic nephropathy (26). In addition, Azab et al showed that higher NLR could be important in prognosis of worsening renal function in diabetic patients. They stated that NLR not only indicates the presence of nephropathy but also can be considered as a factor in the pathogenesis of the disease (27).

So, it seems that evaluating the role of allopurinol on inflammatory factors can be important. In this regard, Goicoechea et al (2010) showed that in patients with moderate $\mathrm{CKD}$ allopurinol treatment reduces inflammation and decelerates the progression of renal disease. Allopurinol also reduces cardiovascular and hospitalization risk. These results however have to be approved in larger prospective trials and are the basis for a hypothesis that still needs to be tested (28).

Although they evaluated C-reactive protein in their study and did not focus on NLR and PLR, it was consistent with our study because of the effect of allopurinol on reducing the inflammatory parameter. Due to few studies on evaluation of the effect of this drug on inflammatory factors in diabetic nephropathy; it is the strength of this study focused on these parameters, but further investigations are necessary.

Finally, GFR did not differ significantly between the two groups in any of the three times before the study and three and six months after the intervention $(P>0.05)$. After six months of study beginning; GFR changes were not significant in any group $(P>0.05)$.

Contrary to the present study, the results of another research suggest that allopurinol may be effective in increasing GFR levels (12). Another study showed that 12 months use of allopurinol could lead to higher GFR in patients without severe GFR, but in patients with very severe GFR, the drug had no effect (29). After a three years follow-up of diabetics nephropathy patients treated by allopurinol, Liu et al showed that the use of this drug was effective in increasing GFR, which is contrary to the present study (13). The reason for this discrepancy may be due to the follow up duration which is different in the 
mentioned studies. Explaining this finding, GFR can be considered the most proper indicator of renal function, thus 24-hour albumin excretion of more than $300 \mathrm{mg}$ and reduction of GFR is an indication of advanced stage of diabetic nephropathy. In fact, chronic kidney disease involves a range of different pathophysiological processes associated with abnormal renal function and progressive decline in GFR levels. Therefore, it is necessary to pay attention to this factor in order to diagnose kidney disease and its progress. It is recommended to do further studies to evaluate the effect of this drug on GFR levels in longterm follow-up. It has been suggested to consider the effectiveness of allopurinol rather than the other drugs such as beta-blockers, calcium channel blockers, diuretics, $\mathrm{ACE}$ and ARBs II in future studies.

\section{Conclusion}

According to the results of the present study, allopurinol can play a significant role in reducing UA, 24-hour urine protein, NLR and PLR levels without significant changes in the patients' blood factors. Additionally, 6 months after the start of the intervention, the GFR changes were not significant in two groups.

\section{Limitations of the study}

The limitation of the present study was comparatively small sample size. So it is suggested to do more investigations with larger sample size.

\section{Authors' contribution}

Conception and design; SM and FKE. Literature search and data acquisition; AM. Drafting the manuscript; MS. Analysis and interpretation of data, critical revision of the manuscript for important intellectual content; SM, FKE and AM. All authors read and approved the final paper.

\section{Conflicts of interest}

The authors declare that they have no competing interests.

\section{Ethical considerations}

Ethical issues (including plagiarism, data fabrication, double publication) have been completely observed by the authors.

\section{Funding/Support}

This work supported by deputy research and technology of Shahrekord University of Medical Sciences (Grant\# 397303).

\section{References}

1. Gaballa M, Farag MK. Predictors of Diabetic Nephropathy. Eur J Med 2013;8:287-296. doi: 10.2478/s11536-012-0055-3

2. Lopez-Parra V, Mallavia B, Egido J, Gomez-Guerrero C. Immunoinflammation in Diabetic Nephropathy: Molecular Mechanisms and Therapeutic Options. In: Chan JSD. Diabetic Nephropathy. InTech; 2012: 127-146.
3. Navarro-González JF, Jarque A, Muros M, Mora C, García J. Tumor necrosis factor-alpha as a therapeutic target for diabetic nephropathy. Cytokine Growth Factor Rev 2009;20:165-73. doi: 10.1016/j.cytogfr.2009.02.005

4. Association AD. Standards of medical care in diabetes-2015 abridged for primary care providers. Clin Diabetes. 2015;33:97. doi:10.2337/diaclin.33.2.97

5. Filiopoulos V, Hadjiyannakos D, Vlassopoulos D. New insights into uric acid effects on the progression and prognosis of chronic kidney disease. Ren Fail. 2012; 34:51020. doi: 10.3109/0886022X.2011.653753

6. Borghi C, Rosei EA, Bardin T, Dawson J, Dominiczak A, Kielstein JT, Manolis AJ, Perez-Ruiz F, Mancia G. Serum uric acid and the risk of cardiovascular and renal disease. J Hypertens. 2015;33:1729-41. doi: 10.1097/ HJH.0000000000000701

7. Latif H, Iqbal A, Rathore R, Butt NF. Correlation between serum uric acid level and microalbuminuria in type-2 diabetic nephropathy. Pak J Med Sci. 2017;33:1371. doi: 10.12669/pjms.336.13224

8. Butler R, Morris AD, Belch JJ, Hill A, Struthers AD. Allopurinol normalizes endothelial dysfunction in type 2 diabetics with mild hypertension. Hypertens. 2000;35:74651. doi: 10.1161/01.HYP.35.3.746

9. Hilgers KF, Veelken R. Type 2 diabetic nephropathy: never too early to treat? J Am Soc Nephrol. 2005; 16:574-5. doi: 10.1681/ASN.2005010083

10. Minami $M$, Ishiyama A, Takagi M, Omata M, Atarashi K. Effects of allopurinol, a xanthine oxidase inhibitor, on renal injury in hypercholesterolemia-induced hypertensive rats. Blood Press. 2005;14(2):120-5. doi: $10.1080 / 08037050510008878$

11. Hostetter TH. Prevention of end-stage renal disease due to type 2 diabetes. N Engl J Med. 2001;345:910-2. doi: 10.1056/ NEJM200109203451209

12. Kanbay M, Ozkara A, Selcoki Y, Isik B, Turgut F, Bavbek N, et al. Effect of treatment of hyperuricemia with allopurinol on blood pressure, creatinine clearence, and proteinuria in patients with normal renal functions. Int Urol Nephrol. 2007;39:1227-33. doi: 10.1007/s11255-007-9253-3

13. Liu P, Chen Y, Wang B, Zhang F, Wang D, Wang Y. Allopurinol treatment improves renal function in patients with type 2 diabetes and asymptomatic hyperuricemia: 3-year randomized parallel-controlled study. Clin Endocrinol. 2015;83:475-82. doi: 10.1111/cen.12673

14. Vupputuri S, Nichols GA, Lau H, Joski P, Thorp ML. Risk of progression of nephropathy in a population-based sample with type 2 diabetes. Diabetes Res Clin Pract. 2011;91:246252. doi: 10.1016/j.diabres.2010.11.022

15. Kramer H, Cao G, Dugas L, Luke A, Cooper R, DurazoArvizu R. Increasing BMI and waist circumference and prevalence of obesity among adults with Type 2 diabetes: the National Health and Nutrition Examination Surveys. J Diabetes Complicat. 2010;24:368-74. doi: 10.1016/j. jdiacomp.2009.10.001

16. Solini A, Ferrannini E. Pathophysiology, prevention and management of chronic kidney disease in the hypertensive patient with diabetes mellitus. J Clin Hypertens. 2011;13:252-7. doi: 10.1111/j.1751-7176.2011.00446.x.

17. Kalk WJ, Raal FJ, Joffe BI. The prevalence, incidence of, and risk factors for, microalbuminuria among urban Africans with type 1 diabetes in South Africa: An inter-ethnic 
study. Int J Diabet Mellitus. 2010;2:148-53. doi: 10.1016/j. ijdm.2010.10.003 .

18. Hovind P, Rossing P, Johnson RJ, Parving HH. Serum uric acid as a new player in the development of diabetic nephropathy. J Ren Nutr. 2011;21:124-7. doi: 10.1053/j. jrn.2010.10.024.

19. Dehghan A, Van Hoek M, Sijbrands EJ, Hofman A, Witteman JC. High serum uric acid as a novel risk factor for type 2 diabetes. Diabetes Care. 2008;31:361-2. doi: 10.2337/ dc07-1276.

20. Maahs DM, Caramori L, Cherney DZ, Galecki AT, Gao C, Jalal D, et al. Uric acid lowering to prevent kidney function loss in diabetes: the preventing early renal function loss (PERL) allopurinol study. Curr Diab Rep. 2013;13:550-9. doi: 10.1007/s11892-013-0381-0.

21. Wei L, Mackenzie IS, Chen Y, Struthers AD, MacDonald TM. Impact of allopurinol use on urate concentration and cardiovascular outcome. Br J Clin Pharmacol. 2011;71:6007. doi: 10.1111/j.1365-2125.2010.03887.x.

22. Kanbay M, Ozkara A, Selcoki Y, Isik B, Turgut F, Bavbek N, et al. Effect of treatment of hyperuricemia with allopurinol on blood pressure, creatinine clearence, and proteinuria in patients with normal renal functions. Int Urol Nephrol. 2007;39(4):1227-33. doi: 10.1007/s11255-007-9253-3.

23. Goicoechea M, de Vinuesa SG, Verdalles U, Ruiz-Caro C, Ampuero J, Rincón A, et al. Effect of allopurinol in chronic kidney disease progression and cardiovascular risk. Clin J Am Soc Nephrol. 2010;5:1388-93. doi: 10.2215/

\section{CJN.01580210.}

24. Sezer S, Karakan S, Atesagaoglu B, Acar FN. Allopurinol reduces cardiovascular risks and improves renal function in pre-dialysis chronic kidney disease patients with hyperuricemia. Saudi J Kidney Dis Transpl. 2014;25:316. doi: $\quad 10.4103 / 1319-2442.128520$.

25. Duran-Salgado MB, Rubio-Guerra AF. Diabetic nephropathy and inflammation. World J Diabetes. 2014;5:393. doi: 10.4239/wjd.v5.i3.393

26. Chung FM, Tsai JC, Chang DM, Shin SJ, Lee YJ. Peripheral total and differential leukocyte count in diabetic nephropathy: The relationship of plasma leptin to leukocytosis. Diabetes Care. 2005;28:1710-7. doi: 10.2337/ diacare.28.7.1710

27. Azab B, Daoud J, Naeem FB, Nasr R, Ross J, Ghimire $\mathrm{P}$, et al. Neutrophil-to-lymphocyte ratio as a predictor of worsening renal function in diabetic patients (3year follow-up study). Ren Fail. 2012;34(5):571-6. doi: 10.3109/0886022X.2012.668741

28. Goicoechea M, de Vinuesa SG, Verdalles U, Ruiz-Caro C, Ampuero J, Rincón A, et al. Effect of allopurinol in chronic kidney disease progression and cardiovascular risk. Clin J Am Soc Nephrol. 2010;5:1388-93. doi: 10.2215/ CJN.01580210

29. Thurston MM, Phillips BB, Bourg CA. Safety and efficacy of allopurinol in chronic kidney disease. Ann Pharmacother. 2013;47(11):1507-16. doi: 10.1177/1060028013504740

Copyright $\odot 2021$ The Author(s); Published by Nickan Research Institute. This is an open-access article distributed under the terms of the Creative Commons Attribution License (http://creativecommons.org/licenses/by/4.0), which permits unrestricted use, distribution, and reproduction in any medium, provided the original work is properly cited. 